\title{
Strength Evaluation on M25 \& M 30 Grades of Self Compaction Concrete by Partial Replacement of Saw Dust in Fine Aggregates
}

\author{
N Shiva Kumar Reddy, P Nagi Reddy
}

\begin{abstract}
Self-compacting concrete (SCC), an ongoing development in solid innovation, has various points of interest over traditional cement. Self-compacting concrete, as the name demonstrates, is a kind of solid that does not require outer or inner compaction, since it progresses toward becoming leveled and combined under its self weight. SCC can spread and fill all edges of the formwork, absolutely by methods for its self-weight, along these lines taking out the need of vibration or any sort of combining exertion.

This report exhibits the potential outcomes of utilizing considered residue to be halfway substitution of fine total in cement. This test examination was performed to assess the quality and strength properties of cement, in which fine total was incomplete, supplanted with saw dust squander. Fine total was supplanted with four rate $(0 \%, 10 \%, 15 \%, 20 \%)$ of saw dust squander by weight. New properties of self-compacting concrete were considered. Pressure test and part rigidity test were done to assess the quality properties of cement at the age of 7,14 , and 28 days.
\end{abstract}

Keywords: Self-compacting concrete (SCC), Saw residue, quality and sturdiness properties of solid, Compression test and part rigidity test.

\section{INTRODUCTION}

Concrete has been and will be, for a significant number of years the most adaptable materials utilized in development. Concrete above all has an edge over other development materials in view of its one of a kind capacity to take any shape in different applications whether it is deliver on the site or whether it is made in a processing plant as a pre-thrown item. Amid the most recent two decades, solid innovation has been experiencing quick enhancement. The creative energy of world without cement is inconceivable. Concrete is a spirit of foundations. Concrete is important to pick up quality in structures. Ordinary solid, which is the blend of bond, fine total, coarse total and water needs restoring to accomplish required quality. So it is required to solution for at least 28 days for good hydration and to accomplish target quality.

In the previous couple of decades inner relieving of cement has picked up ubiquity and its relentlessly advancing from research center field of training. Interior relieving allude to the procedure by which the Hydration of concrete happens on account of accessibility of extra inward water that isn't a

piece of the blending water; "Inside CURING" is regularly additionally alluded as self-restoring. Inside relieved cement can be accomplished by including SELF CURING AGENTS. The idea of inside restored operators is to diminish the water dissipation from the solid and henceforth expanding the water maintenance limit of the solid.

\section{Scope of The Work}

- Based on the point and target referenced in the first areas, the extent of the present examination is illustrated as under:

- Curing is the critical Process the extent that solid structure is concern it requires 28 days of watering under amicable environment.

- This issue prompts inquire about on restoring process which requires less or no water for relieving without bargaining with its compressive quality.

- Thus, above test can be overwhelmed with the assistance of inside restored solid which can be accomplished by including self-relieving added substances, for example, PEG-400

- Fine total was supplanted with four rate $(0 \%, 10 \%, 15 \%$, $20 \%$ ) of saw dust squander by weight.

- Hence, the extent of the work or research is to think about the mechanical qualities of cement, for example, compressive quality, by differing the level of PEG-of $2 \%$ by load of bond for M30 review of cement.

Objective of The Project

- Inside restored concrete with admixture

- PEG 400 is included the solid blend structure

- Fine total is supplanted with Saw dust the accompanying substitution $0,10,15$ and $20 \%$

- Mix evaluations of M20 was finished

- Cubes, Cylinders were threw with blend configuration by including $2 \%$ PEG.

- Finally, quality was determined for every one of the examples.

\section{LITERATURE REVIEW}

- Magda I. Mousa et. al. the mechanical properties of cement containing self-restoring specialists are examined in 


\section{STRENGTH EVALUATION ON M25 \& M 30 GRADES OF SELF COMPACTION CONCRETE BY PARTIAL REPLACEMENT OF SAW DUST IN FINE AGGREGATES}

his paper. In this examination, two materials were chosen as self-restoring specialists with various sums, and the expansion of silica rage was considered. Oneself restoring operators were, pre-doused lightweight total (LECA) and polyethylene-glycol PEG $(\mathrm{CH})$. The outcome demonstrates that solid utilized polyethylene-glycol as self-restoring operator, accomplished higher estimations of mechanical properties than cement with soaked LECA.

- Ya Wei et al explored on inward relieving proficiency of prewetted LWFAS on Concrete Humidity and Autogenous Shrinkage improvement. To all the more likely use inward restoring innovation for solid cements, this examination researches the microstructure and the Desorption properties of sintered fly fiery debris and extended shale LWFAs. The impacts of these two sorts of LWFAs on autogenous shrinkage and inward $\mathrm{RH}$ improvement were tentatively assessed in cement with w/c of 0.3 and 0.4 .

- Siddiqui M. Junaid et. al. exhibited the utilization of shrinkage lessening admixture for example polyethylene glycol (By including 1\% and $1.25 \%$ of PEG-4000 by load of bond) in M40 review of solid (Grade proportion $=1: 2.23: 3.08$ ) which helps in self-restoring with better hydration which decreases shrinkage splits and thus builds quality and is contrasted and that of traditional relieved cement of a similar review. Distinctive examinations were done in the field of self-relieving concrete and some of them are recorded beneath. Scientists found that self-relieving concrete is a compelling substitution to regular cement.

- Mohanraj An et.al, contemplated on "self-relieving concrete joined with polyethylene glycol". The compressive quality of shape for Self-restored concrete is higher than of cement relieved by customary relieving strategy. The split rigidity of self-restored solid example is higher than that of the routinely relieved example. Self-restored concrete is found to have less water ingestion esteems contrasted and concrete relieved by different strategies. Self-restored solid in this way has a less measure of permeable.

- Basil M Joseph, considered on self-restoring cement and PEG400 were utilized as a self-relieving specialist in cement. M20 review of cement is embraced for examination. The creator included $0-1.5 \%$ of PEG400 by load of bond for M20 review concrete from that he discovered 1\% of PEG400 by load of concrete was ideal for M20 review of cement for accomplish great most extreme quality. The creator found that the level of PEG400 gets expanded droop just as compaction factor likewise get expanded.

\section{MATERIALS AND PROPERTIES}

In making any kind of solid, choice and sort of materials is essential as every one of the properties relies upon them.

The accompanying materials are being utilized and are recorded beneath.

$\checkmark$ Cement

$\checkmark$ Fine aggregate (sand)

$\checkmark$ Saw Dust (replacement of Fine aggregate)

$\square$ Water

$\square$ Peg 400

\section{Cement}

The most well-known concrete utilized is an Ordinary Portland Cement (OPC). The Ordinary Portland Cement of
53 review (OPC) adjusting to IS: $8112-1989$ is utilized. A concrete is a folio, a substance utilized in development that sets, solidifies and clings to different materials, restricting them together.

\begin{tabular}{|c|c|c|}
\hline S.No. & CHARACTERISTICS & VALUE \\
\hline 1 & SPECIFIC GRAVITY & 3.15 \\
\hline 2 & NORMAL CONSISTENCY & $31 \%$ \\
\hline
\end{tabular}

\section{Aggregates}

Totals are latent granular materials, for example, sand, rock or pulverized stone that are a final result in their own right. They are likewise the crude materials that are a basic fixing in cement.

Contingent on the size the totals are grouped into two kinds

1) Fine Aggregate

2) Coarse Aggregate

\section{Fine Aggregate}

Fine total are essentially sands won from the land or the marine condition. Fine totals by and large comprise of normal sand or smashed stone with most particles going through a $9.5 \mathrm{~mm}$ sifter. Similarly as with coarse totals these can be from Primary, Secondary or Recycled sources. The choice of fine total is additionally on imperative factor as it straightforwardly influences the quality of cement with the fluctuating usage of water

\begin{tabular}{|c|l|l|}
\hline S.No. & \multicolumn{1}{|c|}{ Physical Properties } & Fine Aggregate \\
\hline 1 & Size and Zone & $4.75 \mathrm{~mm}$ down \\
\hline 2 & Specific gravity & 2.65 \\
\hline 3 & Water Absorption & $1.4 \%$ \\
\hline 4 & Moisture Adsorption & $2 \%$ \\
\hline 5 & Fineness modulus & 3.95 \\
\hline
\end{tabular}

\section{Saw Dust}

The sawdust was sourced from neighborhood wood saw process, close Chengalpattu. The sawdust comprised of chippings from different hardwoods. It was sun dried and kept in waterproof sacks. It was sieved through $4.75 \mathrm{~mm}$ strainer to concrete examples. The saw dust was tried for thickness, dampness substance and fineness modulus in research facility.

Table: Properties of saw dust

\begin{tabular}{|l|l|l|}
\hline \multicolumn{1}{|c|}{ S. No. } & \multicolumn{1}{c|}{ Parameters } & \multicolumn{1}{c|}{ Values } \\
\hline 1 & Fineness modulus & 1.90 \\
\hline 2 & Moisture content & $9.8 \%$ \\
\hline 3 & Bulk density & $615 \mathrm{Kg} / \mathrm{m}^{3}$ \\
\hline
\end{tabular}

\section{Self-Curing Agents (PEG-400):}

The polymers included the blend essentially frame hydrogen securities with water atoms and diminish the synthetic capability of the particles of water which thus decreases the vapor weight, subsequently lessening the rate of dissipation from the surface. The physical and compound properties of PEG-400 are appeared Table 


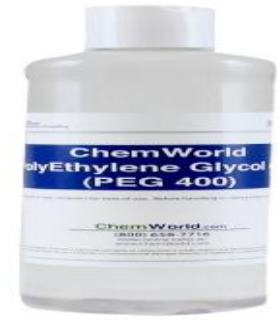

Table: Physical Properties and Chemical Properties PEG400

\begin{tabular}{|c|l|l|}
\hline S.No. & \multicolumn{1}{|c|}{ Appearance } & Clear Liquid or White Solid \\
\hline 1 & Odour & Mild odour \\
\hline 2 & Solubility & Soluble in Water \\
\hline 3 & Density Range & $\begin{array}{l}1.1 \text { to } 1.2 \text { (increases as molecular } \\
\text { weight increases) }\end{array}$ \\
\hline
\end{tabular}

Water:

Water is a vital element of concrete as it really takes an interest in the compound response with bond. Since it serves to from the quality giving concrete gel, the amount and nature of water is required to be investigated cautiously.

Methodology:

Table: Mix Proportions for M30 With PEG400

\begin{tabular}{|l|l|l|l|l|l|l|}
\hline Mix & Saw dust & $\begin{array}{c}\text { Saw dust } \\
\left(\mathbf{K g} / \mathbf{m}^{\mathbf{3}}\right)\end{array}$ & $\begin{array}{c}\text { Cement } \\
\left(\mathbf{K g} / \mathbf{m}^{\mathbf{3}}\right)\end{array}$ & $\begin{array}{c}\text { Fine } \\
\text { aggregate } \\
\left(\mathbf{K g} / \mathbf{m}^{\mathbf{3}}\right)\end{array}$ & $\begin{array}{c}\text { Coarse } \\
\text { aggregate } \\
\left(\mathbf{K g} / \mathbf{m}^{\mathbf{3}}\right)\end{array}$ & $\begin{array}{c}\text { Water } \\
\left(\mathbf{l i t} / \mathbf{~ m}^{\mathbf{3}}\right)\end{array}$ \\
\hline A0 & $0 \%$ & 0 & 394 & 732 & 1139 & 197 \\
\hline A1 & $10 \%$ & 73.2 & 394 & 658.8 & 1139 & 197 \\
\hline A2 & $15 \%$ & 109.8 & 394 & 622.2 & 1139 & 197 \\
\hline A3 & $20 \%$ & 146.4 & 394 & 585.6 & 1139 & 197 \\
\hline
\end{tabular}

\section{Batching and Mixing}

Clumping is procedure of estimating the amounts of cement either by volume or by mass for readiness of solid blend. In this weight clumping technique is received to gauge the amounts of fine total, concrete, coarse total, and Recycled total. For blend extent for configuration were estimated by utilizing gauging balance. The elements of cement in the required amounts were improved into the limit lab solid blender. After through blending i.e., having accomplished uniform shading, serviceable consistency to concrete, the solid was dispatched into plate for throwing examples.

\section{Throwing and Curing of Specimens}

IS standard example were threw with the solid has been put in the standard metallic shape in three layers and compacted with packing pole by giving 25 blows. Before putting the solid in molds, a thin layer of oil was connected for the dividers of the form inside for simple expulsion. At that point molds were put on needle vibrator for $10 \mathrm{r} 15$ seconds in the wake of completing easily on the best surface of examples.

\section{EXPERIMENTAL INVESTIGATION}

In the present examination as per IS norms the accompanying dimensioned examples were threw

- $150 \mathrm{~mm} \times 150 \mathrm{~mm} \times 150 \mathrm{~mm}$ of $3 \mathrm{D}$ shapes,

- $150 \mathrm{~mm} \times 300 \mathrm{~mm}$ of chambers, and

- $150 \mathrm{~mm} \times 150 \mathrm{mmx} 700 \mathrm{~mm}$ of bars.

Coming up next are the tests which was directed in the undertaking:
Quality Tests:

- Compressive quality test

- Split rigidity test

\section{A. Compressive Strength Test}

Solid 3D shapes ofsizes $150 \mathrm{~mm} \times 150 \mathrm{~mm} \times 150 \mathrm{~mm}$ were tried for smashing quality. Compressive quality relies upon heaps of factor, for example, w/c proportion, bond quality, brilliance of solid material and greatness control amid fabricate of cement. These solid shapes are tried by pressure testing machine following 7 days, 14 days 28 days and 56 days relieving. The example is set midway on the base plate of machine and the heap must be apply bit by bit at the rate of $140 \mathrm{~kg} / \mathrm{cm} 2$ every moment till the example falls flat.

\section{B. Split Tensile Strength Test}

The tensile strength of concrete is one of the basic and important properties. Splitting tensile strength test on concrete cylinder is a method to determine the tensile strength of concrete. The concrete is very weak in tension due to its brittle nature and is not expected to resist the direct tension. The concrete develops cracks when subjected to tensile forces. Thus, it is necessary to determine the tensile strength of concrete to determine the load at which the concrete members may crack. The splitting of cylinder is shown in figure. The following relation is used to find out the spilt tensile strength of cylinder (1) Where Ft is split tensile strength, $\mathrm{P}=$ Ultimate load in $\mathrm{KN} \mathrm{L}=$ Length of the cylinder in $\mathrm{mm}, \mathrm{D}=$ Diameter of the cylinder in $\mathrm{mm}$

\section{RESULTS}

The outcomes finished in the present examination are accounted for as Tables and Graphs for different level of reused total as a substitution to coarse total. Coming up next are the rates substitution of bond for example $2 \%$ with PEG 400 and $0,10,15$ and $20 \%$ supplanting of coarse total with reused total.

Table: 4.2. Compressive Strength of cube specimens at age 7 Days

\begin{tabular}{|l|c|c|}
\hline Mix & $\begin{array}{c}\text { Saw } \\
\text { dust }\end{array}$ & $\begin{array}{c}\text { Compressive strength } \\
\text { of specimens for 7 days }\end{array}$ \\
\hline A0 & $0 \%$ & 12.11 \\
\hline A1 & $10 \%$ & 13.33 \\
\hline A2 & $15 \%$ & 14.67 \\
\hline A3 & $20 \%$ & 15.8 \\
\hline
\end{tabular}




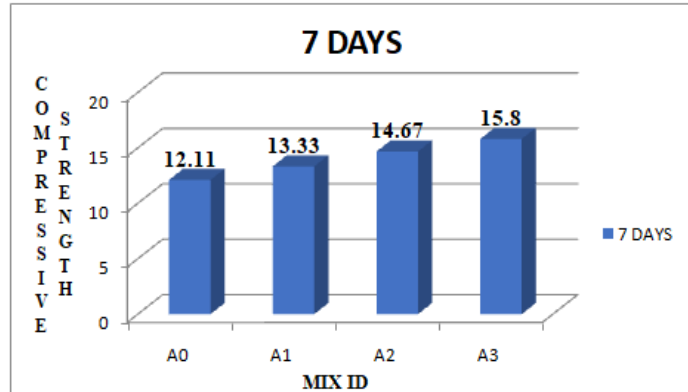

Fig.: 4.3. Compressive Strength of cube specimens at age 7 Days

Table 4.3.: Compressive Strength of cube specimens at

\begin{tabular}{|c|c|c|}
\hline \multicolumn{3}{|c|}{ age 14 Days } \\
\hline Mix & $\begin{array}{c}\text { Saw } \\
\text { dust }\end{array}$ & $\begin{array}{c}\text { Compressive } \\
\text { strength of } \\
\text { specimens for 14 } \\
\text { days }\end{array}$ \\
\hline A0 & $0 \%$ & 25.3 \\
\hline A1 & $10 \%$ & 26.78 \\
\hline A2 & $15 \%$ & 27.11 \\
\hline A3 & $20 \%$ & 24.8 \\
\hline
\end{tabular}

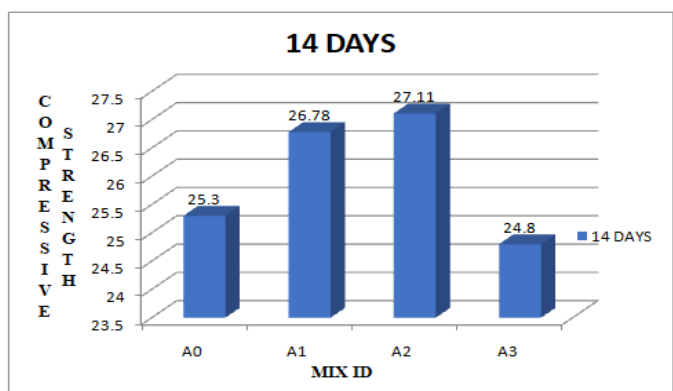

Fig.: 4.4. Compressive Strength of cube specimens at age 14 Days

Table. 4.4.: Compressive Strength of cube specimens at age 28 days

\begin{tabular}{|c|c|c|}
\hline Mix & $\begin{array}{c}\text { Saw } \\
\text { dust }\end{array}$ & $\begin{array}{c}\text { Compressive strength of } \\
\text { specimens for 28 days }\end{array}$ \\
\hline A0 & $0 \%$ & 33.44 \\
\hline A1 & $10 \%$ & 34.56 \\
\hline A2 & $15 \%$ & 36.11 \\
\hline A3 & $20 \%$ & 38.12 \\
\hline
\end{tabular}

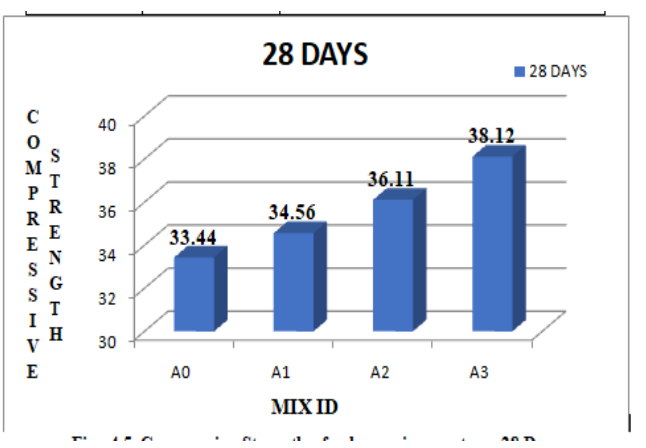

Fig.: 4.5. Compressive Strength of cube specimens at age 28 Days

Table 4.7.: Split-Tensile Strength of cylinder specimens at age 7 Days

\begin{tabular}{|c|c|c|}
\hline \multicolumn{2}{|c|}{\begin{tabular}{c} 
Mi \\
\multicolumn{1}{|c|}{$\begin{array}{c}\text { Saw } \\
\text { dust }\end{array}$}
\end{tabular}} & $\begin{array}{c}\text { Split-tensile strength } \\
\text { of specimens for 7 days }\end{array}$ \\
\hline A0 & $\mathbf{0 \%}$ & 4.1 \\
\hline A1 & $10 \%$ & 6.17 \\
\hline A2 & $15 \%$ & 7.29 \\
\hline A3 & $20 \%$ & 8.41 \\
\hline
\end{tabular}

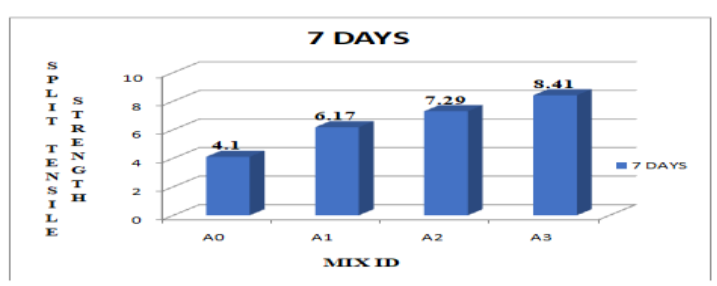

Fig.: 4.8. Table: Split-Tensile Strength of Cylinder Specimens at age 7 Days

Table 4.8.: Split-Tensile Strength of cylinder specimens at age 14 Days

\begin{tabular}{|l|l|c|}
\hline Mix & Saw dust & $\begin{array}{c}\text { Split-tensile } \\
\text { strength of specimens } \\
\text { for 14 days }\end{array}$ \\
\hline A0 & $0 \%$ & 4.38 \\
\hline A1 & $10 \%$ & 4.4 \\
\hline A2 & $15 \%$ & 5.44 \\
\hline A3 & $20 \%$ & 4.52 \\
\hline
\end{tabular}
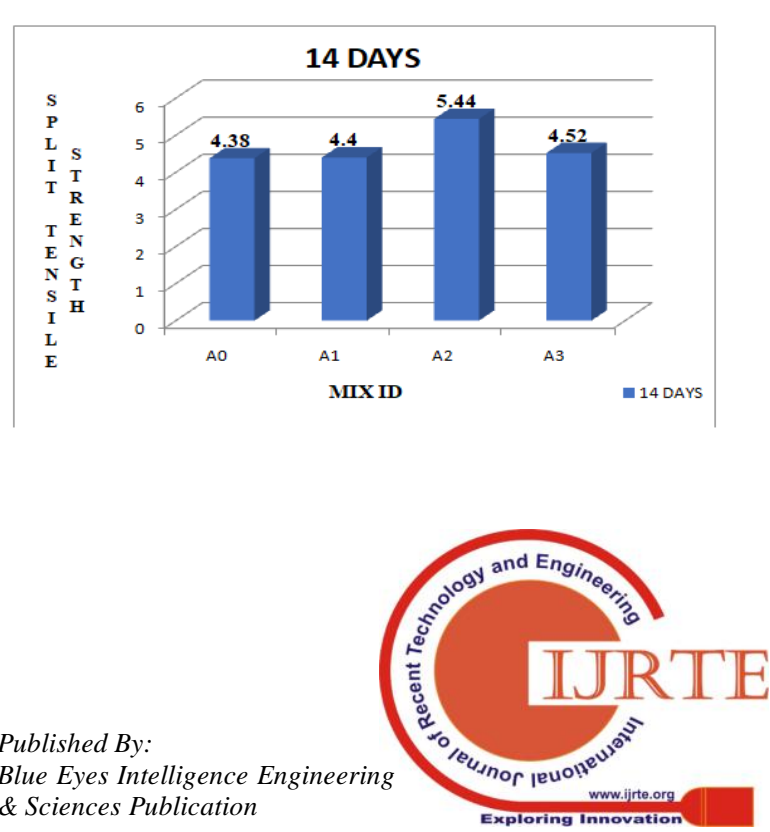


\begin{tabular}{|c|c|c|}
\hline Mix & $\begin{array}{c}\text { Saw } \\
\text { dust }\end{array}$ & $\begin{array}{l}\text { Split-tensile } \\
\text { strength } \\
\text { specimens for 28 } \\
\text { days }\end{array}$ \\
\hline A0 & $0 \%$ & 5.1 \\
\hline A1 & $10 \%$ & 5.5 \\
\hline A2 & $15 \%$ & 6.36 \\
\hline A3 & $20 \%$ & 6.45 \\
\hline
\end{tabular}

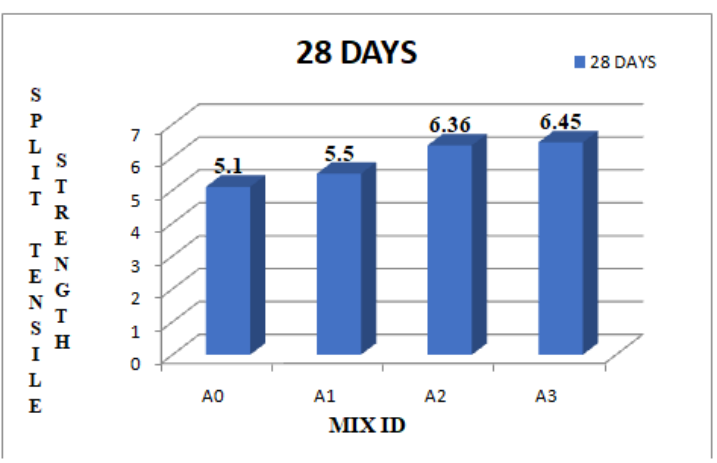

Fig.: 4.10. Split-Tensile Strength of Cylinder Specimens at age 28 Days

\section{CONCLUSIONS}

- The self-relieving specialist PEG-400 was observed to be powerful.

- It was discovered that each review of cement has one ideal level of dose which it requires to give the most extreme quality.

- It was discovered that PEG at an ideal measurements gives some better outcomes while including it in overabundance may diminish the quality of cement

- Compressive quality of cement with $2 \%$ PEG-400 measurements gives higher compressive quality when contrasted with customarily restored cement.

- As the measurements of PEG-400 expands the quality of cement decreases.

- By the utilization of PEG-400 it is seen that the functionality of cement additionally increments and cement winds up flowable.

- We infer that utilization of PEG-400 is a superior choice to shape an inside restored solid which does not require any outer relieving water without trading off with its quality $100 \%$ restoring water can be spared as there is no need of restoring process required for inside relieved cement.

- $15 \%$ replacement fine aggregate with saw dust as fine aggregate is optimum value.

- The cost of conventional concrete was same as internally cured concrete.

Future Scope of Internally Cured Concrete by PEG400:

- It can turn into another training in development field of supplanting ordinary cement with inside relieved cement to skip restoring process.

- Research on inside restored concrete in sweltering and cold climate condition should be possible.

- Many different properties of cement can be concentrate, for example, synthetic and physical properties.

- Taking present situation, sparing water ought to be given more need than cash so with the equivalent monetary variables of cement of both customary and inside relieved solid, we should begin receiving inside restored solid procedure in development field.

\section{REFERENCES}

1. Alexander assmann, hanswolf Reinhardt," a few parts of SAP in Concrete innovation," eighth lie phD symposium in Kgs. Lyngby, Denmark June 20-23,2010

2. H.Beushapusen, M. Gillmer "As The utilization of SAP to lessen splitting of reinforced mortar overlays" University of cape town, Department of structural Engineering, solid Materials And Structural Integrity Research Unit, South Africa, Cement and Concrete Composites 52 (2014), 18

3. O.M.Jensen, "TheUse of Superabsorbent polymers in solid," Concrete International, vol 35, No 1, January1 (2013), Page 48-52

4. Al Nasra,Moayyad, "Streamlining the utilization of Sodium Polyacrylate in plain concrete," Intrnational Journal of Engineering Research and Application ( IJERA) ISSN:2248-9622,Vol.3, Issue 3, May-Jun (2013), Pages 1058-1062

5. Jensen and Hensen, "Autogenous Deformation and RH-Change in Prospective," Cement and solid Research, Vol.31, No.12, Dec.2001, pages 1859-1865

6. Bentz, D.P., -Capillary Porosity Depercolation/Repercolation in Hydrating Cement Pastes by means of Low Temperature Calorimetry Measurements and CEMHYD3D Modeling," Journal of the American Ceramic Society, 89 (8), 2606-2611, 2006.

7. Bentz, D.P., - Influence of Curing Conditions on Water Loss and Hydration in Cement Pastes with and without Fly Ash Substitution,\| NISTIR 6886, U.S. Dept. Business, July 2002.

8. Bentz, D.P., and Snyder, K.A., - Protected Paste Volume in Concrete: Extension to Internal Curing Using Saturated Lightweight Fine Aggregates,\| Cement and Concrete Research. 29, 1863-1867, 1999.

9. Dhir, R.K. Hewlett, P.C. Dyer, T.D., -Mechanisms of water maintenance in bond glues containing a self-relieving agent, $\|$ Magazine of Concrete Research, Vol No 50, Issue No 1, 1998, pp85-90.

10. M.V.JAGANNADHA KUMAR, Volume 1, issue $1 \|$ strength qualities of self-restoring concretell. 